\title{
DNA Methylation Profiles of Donor Nuclei Cells and Tissues of Cloned Bovine Fetuses
}

\author{
Maksym KREMENSKOY1), Yuliya KREMENSKA ${ }^{1)}$, Masako SUZUKI'), Kei IMAI'2), \\ Seiya TAKAHASHI ${ }^{3)}$, Kazuyoshi HASHIZUME ${ }^{4)}$, Shintaro YAGI $^{1)}$ and \\ Kunio SHIOTA ${ }^{1)}$
}

1)Laboratory of Cellular Biochemistry, Animal Resource Science/Veterinary Medical Sciences, Graduate School of Agricultural and Life Sciences, The University of Tokyo, 1-1-1 Yayoi, Bunkyo-ku, Tokyo 113-8657, ${ }^{2}$ Department of Technology, National Livestock Breeding Center, 1 Odakurahara, Odakura, Nishigo, Fukushima 961-8511, ${ }^{3)}$ Reproductive Cell Biology Laboratory, Department of Animal Breeding and Reproduction, National Institute of Livestock and Grassland Science, 2 Ikenodai, Tsukuba, Ibaraki 305-0901, ${ }^{4}$ Laboratory of Veterinary Physiology, Department of Veterinary Medicine, Faculty of Agriculture, Iwate University, 3-18-8 Ueda, Morioka, Iwate 020-8550, Japan

\begin{abstract}
Methylation of DNA in CpG islands plays an important role during fetal development and differentiation because $\mathrm{CpG}$ islands are preferentially located in upstream regions of mammalian genomic DNA, including the transcription start site of housekeeping genes and are also associated with tissue-specific genes. Somatic nuclear transfer (NT) technology has been used to generate live clones in numerous mammalian species, but only a low percentage of nuclear transferred animals develop to term. Abnormal epigenetic changes in the $\mathrm{CpG}$ islands of donor nuclei after nuclear transfer could contribute to a high rate of abortion during early gestation and increase perinatal death. These changes have yet to be explored. Thus, we investigated the genome-wide DNA methylation profiles of CpG islands in nuclei donor cells and NT animals. Using Restriction Landmark Genomic Scanning (RLGS), we showed, for the first time, the epigenetic profile formation of tissues from NT bovine fetuses produced from cumulus cells. From approximately 2600 unmethylated NotI sites visualized on the RLGS profile, at least 35 NotI sites showed different methylation statuses. Moreover, we proved that fetal and placental tissues from artificially inseminated and cloned cattle have tissuespecific differences in the genome-wide methylation profiles of the $\mathrm{CpG}$ islands. We also found that possible abnormalities occurred in the fetal brain and placental tissues of cloned animals.

Key words: Bovine, CpG islands, DNA methylation, Nuclear transfer, RLGS
\end{abstract}

(J. Reprod. Dev. 52: 259-266, 2006)

$\mathbf{P}$ roduction of cloned mammals by nuclear transfer (NT) of adult cells into enucleated oocytes has been successful. However, only a small proportion of reconstructed embryos develop to

Accepted for publication: December 20, 2005

Published online: February 10, 2006

Correspondence: K. Shiota

(e-mail: ashiota@mail.ecc.u-tokyo.ac.jp) term. The highest success rate of all mammalian cloning attempts was achieved in Japanese black cattle [1]. Placentomegaly is a common disorder observed in phenotypically abnormal cloned embryos [2, 3]. In addition, fully grown cloned animals showed many abnormal symptoms, such as pulmonary hypertension, pneumonia, kidney defects, liver defects, and obesity [3]. 
In the mammalian genome, DNA methylation occurs at cytosines of $\mathrm{CpG}$ dinucleotides and is involved in various gene functions, including $X$ chromosome inactivation and gene imprinting [4]. Tissue-dependent differentially methylated regions (T-DMRs) have been identified and revealed to be involved in the regulation of specific gene expression in various tissues and cell types [5-7]. The T-DMRs were identified as widespread in the euchromatin regions of the genome [8], and every tissue and cell had a unique DNA methylation profile consisting of T-DMRs [9-12]. Moreover, the expression of developmental master genes is controlled by methylation of their T-DMRs $[13,14]$. It has been shown that the methylation status of TDMRs changes dynamically with developmental stage [15].

Aberrant DNA methylation in the T-DMRs of fully grown cloned mice has been detected by genome-wide analysis of T-DMRs [16, 17]. Data suggests that complete re-establishment of the DNA methylation profiles was quite difficult to achieve in full-term cloned fetus [18]. Genomewide DNA methylation analysis in T-DMRs is desired to clarify which DNA methylation marks affect the reorganization of correct DNA methylation profiles in nuclear transferred fetuses. In this study, we report genome-wide DNA methylation analysis of donor cells and NT bovine fetuses by Restriction Landmark Genomic Scanning (RLGS). Our results suggest that DNA methylation profiling will be useful for evaluating the success rate of cloned animals.

\section{Materials and Methods}

\section{Cell culture}

Ovaries were obtained from a local abattoir and transported at 25-30 C to the laboratory. Cumulusoocyte complexes (COCs) were aspirated from follicles $2-8 \mathrm{~mm}$ in diameter and placed into sterile plastic tubes. Cumulus cells were harvested from the COCs and cultured in Dulbecco's Modified Eagle's Medium (DMEM, Invitrogen, Carlsbad, CA USA) containing $10 \%$ fetal bovine serum (FBS, JRH, Lenexa, USA), 1 mM L-glutamine (Invitrogen), 100 $\mathrm{U} / \mathrm{ml}$ of penicillin, and $100 \mu \mathrm{g} / \mathrm{ml}$ of streptomycin (Invitrogen). Cultured cells were grown at $37 \mathrm{C}$ in $5 \% \mathrm{CO}_{2}$ at high humidity and were routinely passaged 6-8 times until confluent for genomic
DNA extraction.

\section{NT and control animals}

Bovine NT embryos were produced from cumulus cells as described previously [19]. Control pregnancies were derived by artificial insemination (AI) of Japanese black cows (day $0=$ day of insemination). Diagnosis of pregnancy was made on day 30 of gestation by transrectal ultrasonography (7.5 MHz linear probe, SSD-1700, Aloka, Tokyo, Japan). Fetal viability was confirmed by heartbeat detection 2-3 days prior to slaughter. Fetal and placental tissues of two NT and two AI cows were collected after the cows were slaughtered on days 48 and 59 of gestation. Sex determination was carried out with $Y$ specific primers (5'-AAGCGCCCCATGAATGCATTTATGGT-3' and 5'-ACACTTTAGCCCTCCGATGAGGCTGA-3') and revealed that all animals studied were female. Endometrial tissue (caruncular), placental tissues (cotyledonary and intercolyledonary) and fetal brains from control and cloned animals were collected and separated as detailed by Nikitenko et al. [20] and Regnault et al. [21]. All tissues were immediately placed in liquid nitrogen and stored at $-80 \mathrm{C}$ until processing.

\section{Preparation of genomic DNA}

Genomic DNA was extracted as described previously [12]. Briefly, cells and tissues were suspended in lysis buffer (10 mM Tris-HCl, $\mathrm{pH}$ 8.0, $150 \mathrm{mM}$ EDTA, 1\% SDS) with proteinase K (Merck, Darmstadt, Germany). The mixture was incubated at $55 \mathrm{C}$ for $20 \mathrm{~min}$. Following two phenol/ chloroform/isoamyl alcohol (50:49:1) extractions, genomic DNA was precipitated in ethanol, pelleted, and redissolved in TE buffer $(10 \mathrm{mM}$ Tris$\mathrm{HCl}, \mathrm{pH}$ 7.6, 1 mM EDTA).

\section{Restriction landmark genomic scanning (RLGS)}

The RLGS was performed as described previously [9]. Briefly, $3.5 \mu$ g of genomic DNA was treated with 10 units of Klenow fragment (TaKaRa, Kyoto, Japan) in the presence of $0.4 \mu \mathrm{M}$ dGTP $\alpha \mathrm{S}$, $0.2 \mu \mathrm{MdCTP} \alpha \mathrm{S}$ (Amersham Pharmacia, Buckinghamshire, UK), $0.4 \mu \mathrm{M}$ ddATP and $0.4 \mu \mathrm{M}$ ddTTP (TaKaRa). The DNA was first digested with 20 units of NotI as a landmark enzyme (Nippon Gene, Toyama, Japan) and the cohesive ends were isotopically labeled with 1.3 units of Sequenase Ver 2.0 (USB Corporation, NE) in the presence of 0.33 
Table 1. Distribution of NotI sites in the bovine and mouse genomes

\begin{tabular}{lccccc}
\hline & $\begin{array}{c}\text { Total } \\
\text { number }\end{array}$ & $\begin{array}{c}\text { In non-repetitive } \\
\text { sequence }\end{array}$ & $\begin{array}{c}\text { In repetitive } \\
\text { sequence }\end{array}$ & $\begin{array}{c}\text { Size of } \\
\text { database (bp) }\end{array}$ & RLGS profile \\
\hline Bovine & 8240 & 6529 & 1645 & $2.41 \times 10^{9}$ & 2600 \\
Mouse & 6087 & 3808 & $20.0 \%$ & & $31.6 \%$ \\
& $62.5 \%$ & 2227 & $2.68 \times 10^{9}$ & 1500 \\
& & $36.6 \%$ & & $24.6 \%$ \\
\hline
\end{tabular}

The genomic sequence data was downloaded from the UCSC genome browser site (http://genome.ucsc.edu/) and analyzed by Perl script as described previously [23]. Mouse genome: build 33 assemblies (mm5, May 2004). Bovine genome: btau_1.0 assembly (bosTau1, Sep 2004). Note that in spite of similar genome size, the number of NotI sites is higher in the bovine genome compared to those of the mouse. Moreover, in the bovine genome, $79.2 \%$ of all NotI sites are localized in non-repetitive sequences.

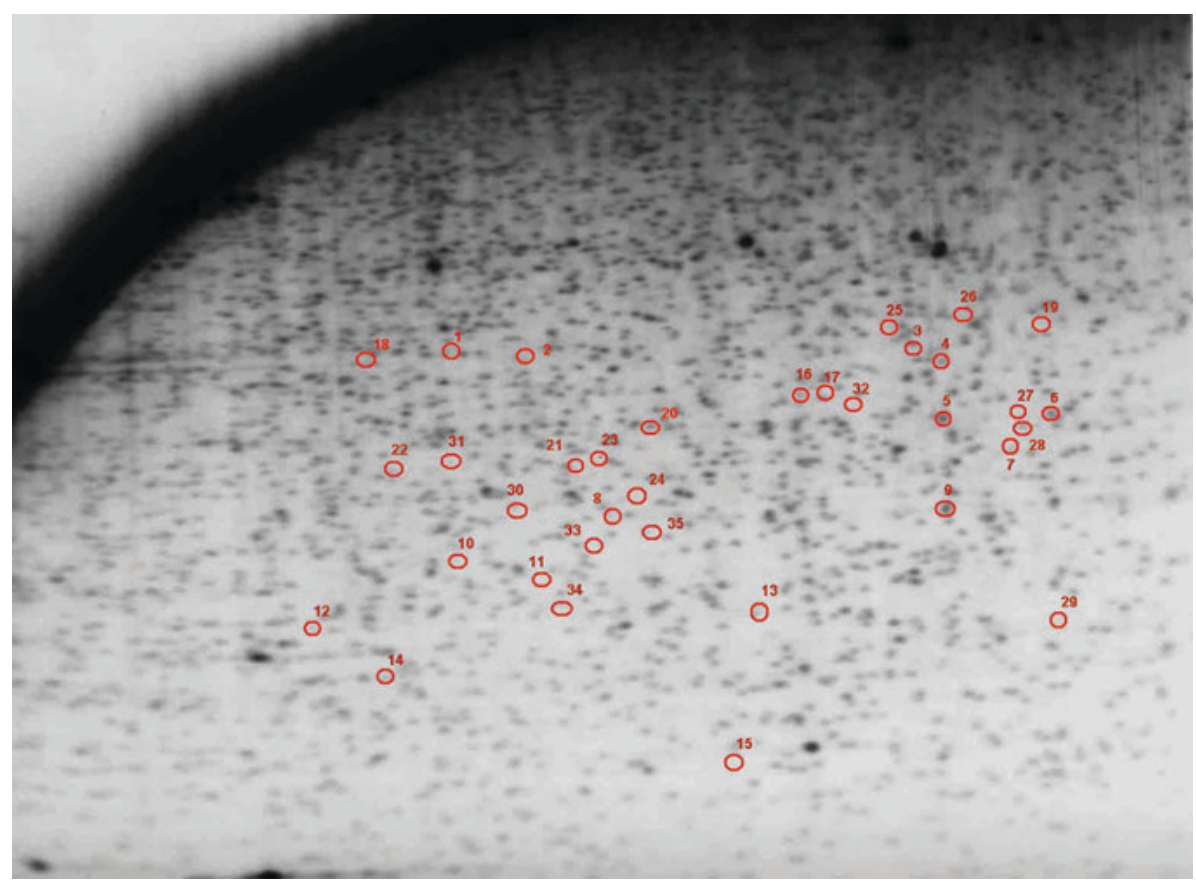

Fig. 1. Typical RLGS profile showing genome-wide DNA methylation status in various CpG islands of the bovine DNA. Approximately 2600 NotI sites appeared as spots on a single RLGS profile. From them, 35 spots (open red circles with numbers) are methylated differently among the DNA of the cumulus cells, ICFM, and fetal brains of the AI and NT animals. These NotI sites were named tissue-dependent differentially methylated regions or T-DMRs.

$\mu \mathrm{M}[\alpha-32 \mathrm{P}] \mathrm{dCTP}$ and $0.33 \mu \mathrm{M}[\alpha-32 \mathrm{P}] \mathrm{dGTP}$ (Amersham). The labeled DNA was then treated with 20 units of PvuII (Nippon Gene) and subjected to first dimension electrophoresis in a $0.9 \%$ agarose disc gel for approximately $23 \mathrm{hrs}$ at $230 \mathrm{~V}$. The DNA fragments in the gel were treated with 1.000 units of PstI (Nippon Gene). The second electrophoresis was carried out in $5 \%$ polyacrylamide gel for $20 \mathrm{hrs}$ at $150 \mathrm{~V}$. The resulting gel was dried and exposed to $X$-ray film (Kodak, XAR 5, Eastman Kodak, Rochester, NY) for 2-3 weeks at $-80 \mathrm{C}$. The spot profile was reproduced at least two times. 


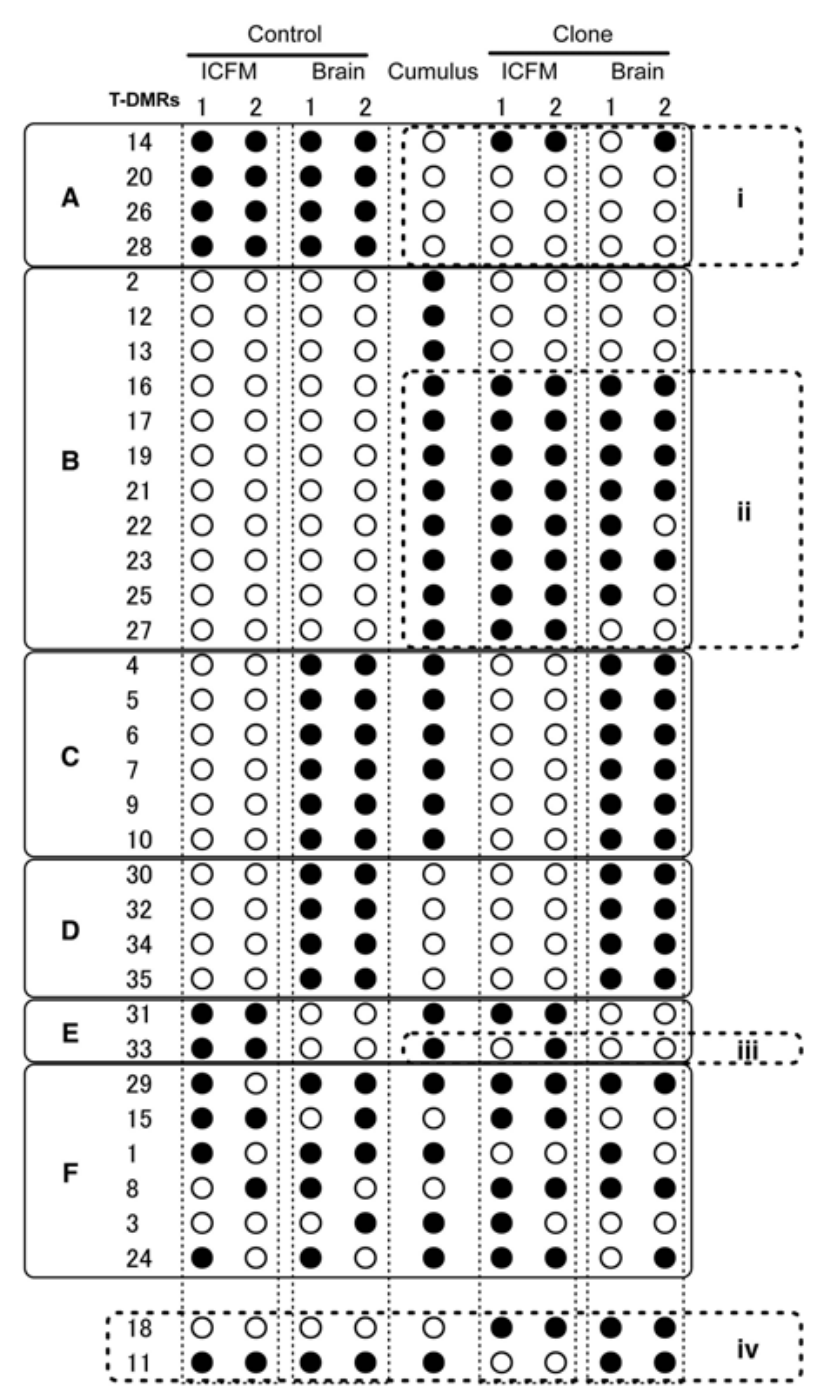

Fig. 2. Methylation profiles of T-DMRs among donor nuclei cells, and control and cloned fetal tissues. Open and closed circles represent the unmethylated and methylated status of NotI sites, respectively. T-DMRs have been combined into several groups as follows: tissue-specifically methylated in cumulus cells (A, B) ICFM (C), and brain (D, E). Arbitrarily methylated loci were also detected (F). Aberrant methylated TDMRs in cloned fetuses are represented in groups I, II, III, and IV.

\section{Results}

Analysis of the DNA methylation profiles of the bovine genome

Profiles of DNA methylation of T-DMRs using RLGS with NotI methyl-sensitive restriction enzyme as a landmark enzyme have been produced for the mouse, rat, and human genomes
[9, 11, 22]. These RLGS profiles represent the DNA methylation patterns of thousands of NotI sites that are mainly located in genic regions [23]. Bioinformatic analysis of bovine draft genome sequence data indicated that $79 \%$ of NotI sites are distributed in non-repetitive sequences (Table 1), suggesting that RLGS profiles of the bovine genome show DNA methylation patterns of NotI sites corresponding to unique sequences widespread in the entire genome.

We used RLGS to analyze the DNA methylation profiles of fetuses resulting from NT, AI, and donor nuclei cells. Approximately 2600 NotI sites were visualized as spots on a single bovine RLGS profile (Fig. 1). The numbers of NotI sites estimated from the draft sequence data from mouse and bovine genomes were compared in Table 1 . In contrast to the 1500 RLGS-detectable mouse NotI sites (24.6\%), the efficiency of bovine RLGS analysis is higher, revealing 2600 NotI sites or $31.6 \%$ of all genomic NotI sites.

\section{Bovine fetus-specific T-DMRs}

We previously showed that aberrant DNA methylation mainly occurred in T-DMRs [8]. To investigate the establishment of methylation profiles in cloned bovine fetuses, we compared their epigenetic profiles with those of donor cumulus cells and tissues from fetuses obtained by artificial insemination. Intercotyledonal fetal membranes (ICFM) were used as placental tissue and fetal brain as fetal tissue for this study. Although almost all spots in the RLGS profiles matched each other, there were fifteen cumulusspecific T-DMRs: four hypo-methylated (Fig. 2-A) and eleven hyper-methylated regions (Fig. 2-B). We found six NotI sites specifically hypomethylated in the ICFM (Fig. 2-C), and four specifically hyper-methylated (Fig. 2-D) and two hypo-methylated T-DMRs (Fig. 2-E) in the brain tissue. Six arbitrarily methylated loci were observed with methylation profiles that were not conserved among individuals (Fig. 2-F).

\section{DNA methylation status of cloned animals}

We then analyzed the RLGS profiles of the ICFM and brains of cloned fetuses to examine how adequately the DNA methylation profiles of the cloned fetuses could be established from those of the donor nuclei genome. The spots on the RLGS profiles of both types of tissue from the cloned 


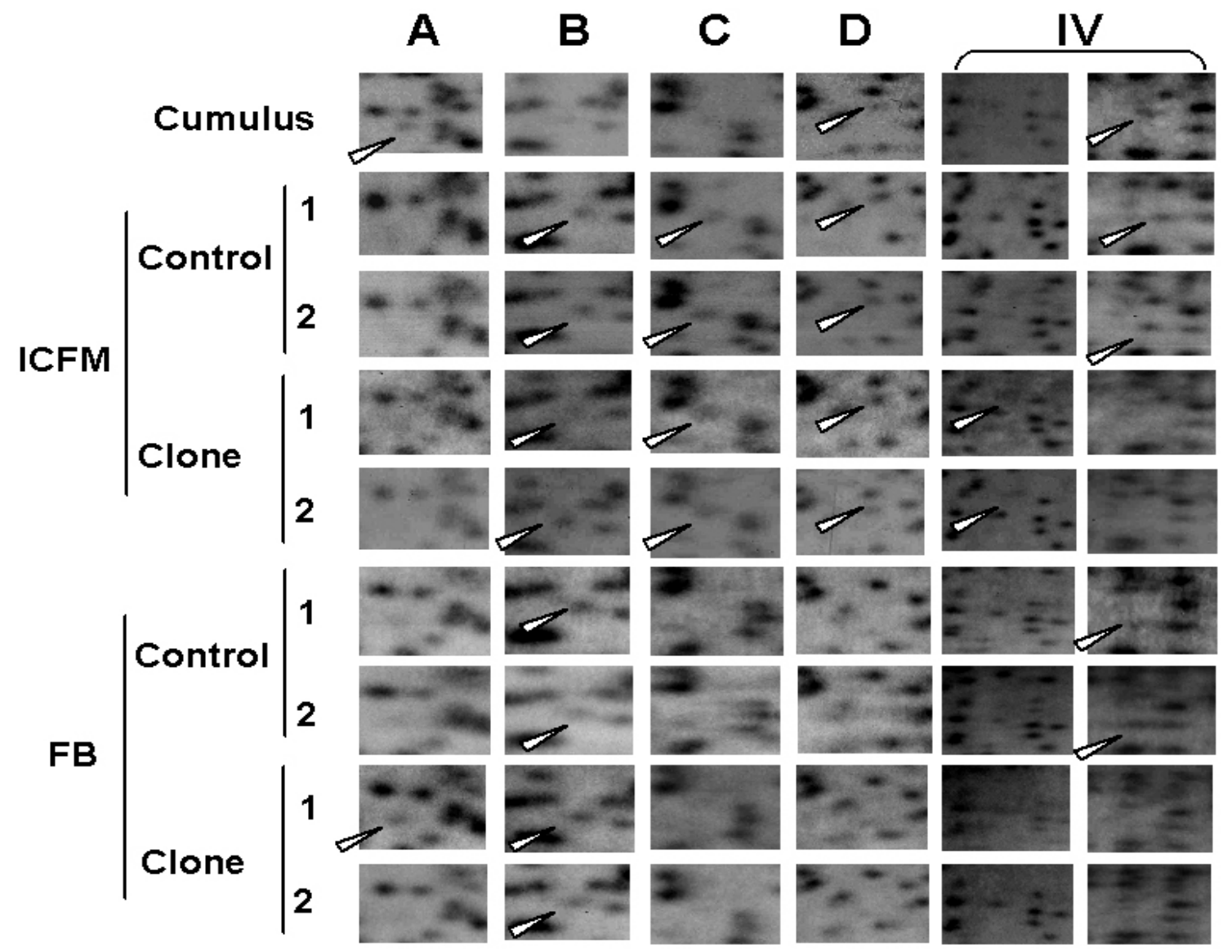

Fig. 3. Location and appearance of spots corresponding to NotI sites on RLGS profiles. A, B, C, D, and IV correspond to the groups displayed in Fig. 2. Arrowheads indicate detectable RLGS spots. (ICFM, intercotyledonal fetal membrane; FB, fetal brain)

bovine fetuses were nearly identical with those of the AI animals; however, aberrantly methylated loci were found in the cloned animals as shown in Fig. 3. Hyper- and hypo-methylation specific to cloned animals (Fig. 2-IV) were observed in two loci. Some arbitrarily methylated loci in the control animals also appeared in the cloned animals (Fig. 2F).

In cumulus-specific T-DMRs, the methylation profiles of the cloned animals were different from those found in the T-DMRs of ICFM and fetal brains. The methylation profiles of eight of nine TDMRs were established in the brains and ICFM of the cloned animals (Fig. 2-III). However, twelve of fifteen aberrantly methylated loci were found to be methylated in the same manner as the cumulus cells (Fig. 2-I, II).

\section{Discussion}

In this study, we compared the DNA methylation patterns of donor cells with those of fetal tissues and found genome-wide alterations in DNA methylation patterns after nuclear transfer. Also, we discovered some aberrantly methylated loci in the cloned fetal tissue. This data supports previous observations in the cloned mouse [16]. As DNA methylation is involved in regulation of gene function [4, 24], failure to reestablish previous DNA methylation patterns appears to be a major cause of cloning rate inefficiency [18].

Incorrect DNA methylation during early developmental stages has been reported previously [25-27]. Moreover, delayed and insufficient DNA demethylation was observed during early developmental stage in bovine cloned embryos [28, 29]. The mammalian genome mainly consists of 
non-genic repetitive sequences [30-32], and these repetitive sequences have been shown to be hypermethylated. Therefore, global analysis of genome methylation should reflect the methylation level of these repetitive sequences [33]. In contrast, RLGS displays the methylation profiles of NotI sites, which are located in non-repetitive sequences and are often in CpG islands (Table 1). Over half of the $\mathrm{CpG}$ islands are localized in promoter regions [34, 35], and their methylation statuses have been shown to be involved in the regulation of tissuespecific gene expression [36]. Thus, it is possible that the aberrant methylation in the T-DMRs found in the cloned animals by RLGS could cause deleterious effects on development of these animals.

In the cloned bovine fetuses, we found that aberrant methylation occurred in the T-DMRs of donor cumulus cells. Insufficient and slow demethylation has been reported in early cloned bovine embryos [28, 29, 37]. In addition, another study reported that the hyper-methylation observed in donor cells was retained in cloned blastocysts [38]. In this study, incorrect inheritance of methylation status was observed in both hypo- and hyper methylated T-DMRs (Fig. 2-II, III). Insufficient global demethylation may not be the sole mechanism for aberrant DNA methylation profiles. Furthermore, these profiles could not be explained by loss of global methylation that has been observed in some NT fetuses undergoing normal pregnancies [39].

Skewed X chromosome inactivation [40] and loss of DNA methylation information in imprinted genes [41] have occurred in cloned mice. In this study, we observed incorrect DNA methylation statuses in cloned tissues that seemed to be inherited from donor nuclei, especially in the TDMRs of donor cells, since all cell types have distinct tissue-specific DNA profiles [11]. Analysis of locus specific reestablishment of DNA methylation status will help us to understand how proper DNA methylation and demethylation occurs during mammalian fetal development.

\section{Acknowledgments}

We thank Dr. Maddy Roberts for proofreading the manuscript.

\section{References}

1. Yanagimachi R. Cloning: experience from the mouse and other animals. Mol Cell Endocrinol 2002; 187: 241-248.

2. Wakayama T, Yanagimachi R. Cloning the laboratory mouse. Semin Cell Dev Biol 1999; 10: 253258.

3. Cibelli JB, Campbell KH, Seidel GE, West MD, Lanza RP. The health profile of cloned animals. Nat Biotechnol 2002; 20: 13-14.

4. Bird A. DNA methylation patterns and epigenetic memory. Genes Dev 2002; 16: 6-21.

5. De Smet $C$, Lurquin $C$, Lethe $B$, Martelange $V$, Boon T. DNA methylation is the primary silencing mechanism for a set of germ line- and tumorspecific genes with a CpG-rich promoter. Mol Cell Biol 1999; 19: 7327-7335.

6. Cho JH, Kimura H, Minami T, Ohgane J, Hattori N, Tanaka S, Shiota K. DNA methylation regulates placental lactogen I gene expression. Endocrinology 2001; 142: 3389-3396.

7. Imamura $\mathrm{T}$, Ohgane J, Ito $\mathrm{S}$, Ogawa $\mathrm{T}$, Hattori $\mathbf{N}$, Tanaka S, Shiota K. CpG island of rat sphingosine kinase-1 gene: tissue-dependent DNA methylation status and multiple alternative first exons. Genomics
2001; 76: 117-125.

8. Hattori $\mathbf{N}$, Abe $T$, Hattori $\mathbf{N}$, Suzuki $M$, Matsuyama T, Yoshida S, Li E, Shiota K. Preference of DNA methyltransferases for CpG islands in mouse embryonic stem cells. Genome Res 2004, 14: 1733-1740.

9. Ohgane J, Aikawa J, Ogura A, Hattori N, Ogawa T, Shiota K. Analysis of CpG islands of trophoblast giant cells by restriction landmark genomic scanning. Dev Genet 1998; 22: 132-140.

10. Ohgane J, Hattori N, Oda M, Tanaka S, Shiota K. Differentiation of trophoblast lineage is associated with DNA methylation and demethylation. Biochem Biophys Res Commun 2002; 290: 701-706.

11. Shiota K, Kogo Y, Ohgane J, Imamura T, Urano A, Nishino K, Tanaka S, Hattori N. Epigenetic marks by DNA methylation specific to stem, germ and somatic cells in mice. Genes Cells 2002; 7: 961-969.

12. Kremenskoy M, Kremenska $\mathbf{Y}$, Ohgane J, Hattori N, Tanaka S, Hashizume K, Shiota K. Genomewide analysis of DNA methylation status of $\mathrm{CpG}$ islands in embryoid bodies, teratomas, and fetuses. Biochem Biophys Res Commun 2003; 311: 884-890.

13. Hattori N, Nishino K, Ko YG, Hattori N, Ohgane J, 
Tanaka S, Shiota K. Epigenetic control of mouse Oct-4 gene expression in embryonic stem cells and trophoblast stem cells. J Biol Chem 2004; 279: 1706317069.

14. Nishino K, Hattori N, Tanaka S, Shiota K. DNA methylation-mediated control of Sry gene expression in mouse gonadal development. J Biol Chem 2004; 279: 22306-22313.

15. Ko YG, Nishino K, Hattori N, Arai Y, Tanaka S, Shiota K. Stage-by-stage change in DNA methylation status of Dnmt1 locus during mouse early development. J Biol Chem 2005; 280: 9627-9634.

16. Ohgane J, Wakayama T, Kogo Y, Senda S, Hattori N, Tanaka S, Yanagimachi R, Shiota K. DNA methylation variation in cloned mice. Genesis 2001; 30: 45-50.

17. Ohgane J, Wakayama T, Senda S, Yamazaki Y, Inoue $K$, Ogura A, Marh J, Tanaka S, Yanagimachi $\mathbf{R}$, Shiota K. The Sall3 locus is an epigenetic hotspot of aberrant DNA methylation associated with placentomegaly of cloned mice. Genes Cells 2004; 9: 253-260.

18. Shiota $\mathbf{K}$, Yanagimachi R. Epigenetics by DNA methylation for development of normal and cloned animals. Differentiation 2002; 69: 162-166.

19. Patel OV, Yamada O, Kizaki K, Takahashi T, Imai K, Takahashi S, Izaike Y, Schuler LA, Takezawa T, Hashizume K. Expression of trophoblast cellspecific pregnancy-related genes in somaticcellcloned bovine pregnancies. Biol Reprod 2004; 70 : 1114-1120.

20. Nikitenko L, Morgan G, Kolesnikov SI, Wooding FBP. Immunocytochemical and in situ hybridization studies of the distribution of calbindin D 9k in the bovine placenta throughout pregnancy. J Histchem Cytochem 1998; 46: 679-688.

21. Regnault TRH, Orbus RJ, De Vrijer B, Davidsen ML, Galan HL, Wilkening RB, Anthony RV. Placental expression of VEGF, PIGF, and their receptors in a model of placental insufficiencyintrauterine growth restriction (PI-IUGR). Placenta 2002; 23: 132-144.

22. Nagai H, Kim YS, Yasuda T, Ohmachi Y, Yokouchi H, Monden M, Emi M, Konishi N, Nogami M, Okumura K, Matsubara K. A novel sperm-specific hypomethylation sequence is a demethylation hotspot in human hepatocellular carcinomas. Gene 1999; 237: 15-20.

23. Fazzari MJ, Greally JM. Epigenomics: beyond CpG islands. Nat Rev Genet 2004; 5: 446-455.

24. Shiota K. DNA methylation profiles of $\mathrm{CpG}$ islands for cellular differentiation and development in mammals. Cytogenet Genome Res 2004; 105: 325-334.

25. Kang YK, Koo DB, Park JS, Choi YH, Chung AS, Lee KK, Han YM. Aberrant methylation of donor genome in cloned bovine embryos. Nat Genet 2001; 28: $173-177$.
26. Fairburn HR, Young LE, Hendrich BD. Epigenetic reprogramming: how now, cloned cow? Curr Biol 2002; 12: R68-70.

27. Dean W, Lucifero D, Santos F. DNA methylation in mammalian development and disease. Birth Defects Res C Embryo Today 2005; 75: 98-111.

28. Bourc'his D, Le Bourhis D, Patin D, Niveleau A, Comizzoli P, Renard JP, Viegas-Pequignot E. Delayed and incomplete reprogramming of chromosome methylation patterns in bovine cloned embryos. Curr Biol 2001; 11: 1542-1546.

29. Kang YK, Park JS, Koo DB, Choi YH, Kim SU, Lee KK, Han YM. Limited demethylation leaves mosaic-type methylation states in cloned bovine pre-implantation embryos. EMBO J 2002; 21: 10921100.

30. International Human Genome Sequencing Consortium. Initial sequencing and analysis of the human genome. Nature 2001; 409: 860-921.

31. Venter JC, Adams MD, Myers EW, Li PW, Mural RJ, Sutton GG, Smith HO, Yandell M, Evans CA, Holt RA, et al. The sequence of the human genome. Science 2001; 291: 1304-1351.

32. Mouse Genome Sequencing Consortium. Initial sequencing and comparative analysis of the mouse genome. Nature 2002; 420: 520-562.

33. Kim SH, Kang YK, Koo DB, Kang MJ, Moon SJ, Lee KK, Han YM. Differential DNA methylation reprogramming of various repetitive sequences in mouse preimplantation embryos. Biochem Biophys Res Commun 2004; 324: 58-63.

34. Suzuki Y, Tsunoda T, Sese J, Taira H, MizushimaSugano J, Hata H, Ota T, Isogai T, Tanaka T, Nakamura Y, Suyama A, Sakaki Y, Morishita S, Okubo K, Sugano S. Identification and characterization of the potential promoter regions of 1031 kinds of human genes. Genome Res 2001; 11: 677-684.

35. Antequera F. Structure, function and evolution of CpG island promoters. Cell Mol Life Sci 2003; 60: 1647-1658.

36. Song F, Smith JF, Kimura MT, Morrow AD, Matsuyama T, Nagase H, Held WA. Association of tissue-specific differentially methylated regions (TDMs) with differential gene expression. Proc Natl Acad Sci USA 2005; 102: 3336-3341.

37. Dean W, Bowden L, Aitchison A, Klose J, Moore T, Meneses JJ, Reik W, Feil R. Altered imprinted gene methylation and expression in completely ES cellderived mouse fetuses: association with aberrant phenotypes. Development 1998; 125: 2273-2282.

38. Dean W, Santos F, Stojkovic M, Zakhartchenko V, Walter J, Wolf E, Reik W. Conservation of methylation reprogramming in mammalian development: aberrant reprogramming in cloned embryos. Proc Natl Acad Sci USA 2001; 98: 1373413738. 
39. Cezar GG, Bartolomei MS, Forsberg EJ, First NL, Bishop MD, Eilertsen KJ. Genome-wide epigenetic alterations in cloned bovine fetuses. Biol Reprod 2003; 68: 1009-1014.

40. Senda S, Wakayama T, Yamazaki Y, Ohgane J, Hattori N, Tanaka S, Yanagimachi R, Shiota K. Skewed X-inactivation in cloned mice. Biochem
Biophys Res Commun 2004; 321: 38-44.

41. Young LE, Schnieke AE, McCreath KJ, Wieckowski S, Konfortova G, Fernandes K, Ptak G, Kind AJ, Wilmut I, Loi P, Feil R. Conservation of IGF2-H19 and IGF2R imprinting in sheep: effects of somatic cell nuclear transfer. Mech Dev 2003; 120: 1433-1442. 